\title{
Should Psychotherapy be taught to Psychiatric Residents? A Debate.
}

Donald W. Black, MD

Burroughs-Wellcome Fellow

John Ascher, MD

Burroughs-Wellcome Fellow

Hal Cash, MD

Burroughs-Wellcome Fellow

John Markowitz, MD

Burroughs-Wellcome Fellow

Paul Hamburg, MD

Burroughs-Wellcome Fellow

Follow this and additional works at: https://jdc.jefferson.edu/jeffjpsychiatry

Part of the Psychiatry Commons

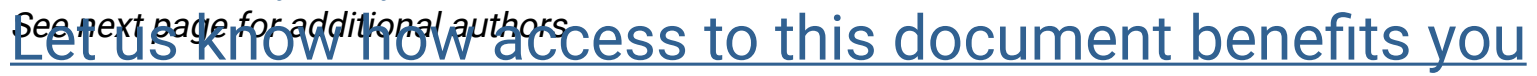

\section{Recommended Citation}

Black, MD, Donald W.; Ascher, MD, John; Cash, MD, Hal; Markowitz, MD, John; Hamburg, MD, Paul; Satinover, MD, Jeffrey; and Mellow, MD, Alan (1987) "Should Psychotherapy be taught to Psychiatric Residents? A Debate.," Jefferson Journal of Psychiatry. Vol. 5 : Iss. 1 , Article 7.

DOI: https://doi.org/10.29046/JJP.005.1.005

Available at: https://jdc.jefferson.edu/jeffjpsychiatry/vol5/iss1/7

This Article is brought to you for free and open access by the Jefferson Digital Commons. The Jefferson Digital Commons is a service of Thomas Jefferson University's Center for Teaching and Learning (CTL). The Commons is a showcase for Jefferson books and journals, peer-reviewed scholarly publications, unique historical collections from the University archives, and teaching tools. The Jefferson Digital Commons allows researchers and interested readers anywhere in the world to learn about and keep up to date with Jefferson scholarship. This article has been accepted for inclusion in Jefferson Journal of Psychiatry by an authorized administrator of the Jefferson Digital Commons. For more information, please contact: JeffersonDigitalCommons@jefferson.edu. 


\section{Should Psychotherapy be taught to Psychiatric Residents? A Debate.}

\section{Authors}

Donald W. Black, MD; John Ascher, MD; Hal Cash, MD; John Markowitz, MD; Paul Hamburg, MD; Jeffrey Satinover, MD; and Alan Mellow, MD 


\title{
Should Psychotherapy be Taught to Psychiatric Residents? A Debate
}

\author{
Donald W. Black, M.D. \\ John Ascher, M.D. \\ Hal Cash, M.D. \\ John Markowitz, M.D. \\ Paul Hamburg, M.D. \\ Jeffrey Satinover, M.D. \\ Alan Mellow, M.D.
}

OPENING REMARKS BY DR. MELLOW

Much of this discussion was inspired by a debate held at the 1984 APA Annual Meeting, entitled “Does Psychodynamic Theory Have Little Relevance to Contemporary Psychiatric Care?" We saw the need for a debate, residentgenerated, that would address a corollary issue in residency training.

Our program will include an introduction, a debate involving statements for the affirmative, that is, that psychotherapy should be taught to psychiatric residents, and two statements for the negative, that psychotherapy should not be taught to psychiatric residents. Concluding remarks will follow.

If our title is provocative, if what we have to say inspires you to participate in this critical discussion, either by way of pleasing, stimulating, or offending you, then we have served our purpose well.

\section{INTRODUCTION BY DR. CASH}

The question before us derives, in part, from the debate at the 1984 APA convention in Los Angeles. At that debate, Drs. John Nemiah and Robert Michels argued that there was a place for psychodynamic theory in modern psychiatric care, while Drs. Donald Klein and Donald Goodwin argued that there was not. Dr. Michels suggested that psychotherapy provides us with perhaps the richest understanding of what happens between patient and physician, and urged us not to trade a brainless psychiatry for a mindless one. For Dr. Goodwin, however, psychoanalysis is an unwieldy, outmoded beast. Quoting Peter Medewar, Goodwin stated that psychoanalysis is "an end-product, like a dinosaur or a zeppelin ... which will remain forever one of the saddest and strangest of all landmarks in the history of twentieth century thought" (1). We

Presented as a workshop at the Annual Meeting of the American Psychiatric Association, May 21, 1985. The participants were all Burroughs-Wellcome fellows and third-or fourth-year residents at the time of the presentation. 
thought it would be interesting to continue the debate as it pertains to residency training.

Certainly, the turbulence in psychiatry is well reflected in the four-year apprenticeship that we all undergo as residents. It might be helpful to briefly review the origins of this turbulence. There have been far-reaching changes in the focus of psychiatry in the last decade. Until the $1950 \mathrm{~s}$, there were two quite disparate systems. Inpatient care was custodial, and the psychiatrist's world was confined to outpatient psychoanalysis. With the introduction of the psychotropic drugs, psychiatry was no longer synonymous with psychoanalysis alone. The symptomatic relief that the new drugs provided resulted in the emptying of state hospitals and the return of patients to the community. The patient population shifted from the wealthy and learned to the more disturbed and disadvantaged. Treatment was more often directed at immediate needs, such as the management of psychosis in the outside world, as opposed to more leisurely personal growth. Correspondingly, the emphasis of care shifted from the individual to larger networks, such as the family or community, requiring the increasing involvement of non-physicians. With the change in the patient population came the need for new approaches and new definitions of the psychiatrist's role.

Since psychiatry bridges biological, psychological, and social realms, it is especially vulnerable to changes in societal values. The last few decades have seen explosive sociological changes, including changes in the concept of the family, liberalization of sexual attitudes, and the emergence of a drug culture. Further, health care systems have become increasingly accountable to financial and political pressures. More than any other aspect of psychiatry, psychotherapy has been affected by these burgeoning forces. Questions of appropriateness, efficacy and cost-effectiveness have resulted in a diminished role for dynamic psychotherapy.

So what should be taught? As I was preparing this introduction, I realized that the question made me uneasy. Perhaps it is fortunate that the blocks of time in my working day leave little time for reflection. Inpatient crises, outpatient hours, on-call responsibilities, didactics, and supervision are not conducive to pondering what I should be doing. There have been some radical changes in my own department in the last year, which while stimulating, are also anxietyprovoking. What was once a biological bastion looks more and more like a Boston enclave. As my anxiety mounted, I resorted to a favorite retreat: Sherlock Holmes on Masterpiece Theater. Vincent Price was pondering Holmes' extraordinary worldwide following. Quoting Rex Stout, Price asked: "Why all this devotion to a man who was intensely prejudiced, imperious, often bad tempered, thoughtless with people who might look to him for a little kindness, capable of an unmerited snub, grossly self-indulgent, arrogant, self-opinionated and decidedly touchy about trivialities?" The answer, as Stout suggests, is that Holmes is the embodiment of man's dearest and most stubborn conceit - that reason is in control (although it almost never is). 
This, I think, is the question for psychiatry, too. What do we do with unreasoning emotions? How do we quantify and qualify unreason, and how do we handle the anxiety that it engenders in us all?

\section{THE FIRST STATEMENT FOR THE AFFIRMATIVE BY DR. SATINOVER}

Psychiatry is undergoing a crisis of identity. At times we find ourselves casting about for ways of rescuing it. In fact, the existence of this debate points to the crisis of identity which the field, as a whole and within its individual members, is going through. Can you imagine a convention of airline pilots getting together to debate the question: "Should pilots learn to fly?" This debate, sparked by the proposal to eliminate psychotherapy training from psychiatric residency, and indeed possibly to change the field of psychiatry to one in which the psyche is essentially not a part of our conceptualization, originates from our attempts to address a variety of concerns. The argument is related to a larger debate now raging in the field of psychiatry of whether or not psychotherapy is useful in the practice of psychiatry, and in fact is based on similar microeconomic concerns: cost-containment, cost-effectiveness, and redundancy of service. At the heart of these arguments is the concept that, within a competitive marketplace, variants of a product may have only marginal differences. We have seen this happen already in other fields. The soft drink industry is one illustration. For the same reason that Coca-Cola ${ }^{\circledR}$ changed its formula, in order to increase marketability, so it is proposed should we.

Like you, I am already familiar with the various anti-psychotherapy arguments: Its purported lack of efficacy, the difficulty of substantiating its performance by statistically rigorous methods, and the fact that it is a service also offered by other health care professionals. These arguments are not only disputable, but they do not even move me. The studies which demonstrate the efficacy of psychotherapy play little role in my commitment to it, and the studies which demonstrate its lack of efficacy play an equally small role in my criticisms of it. I think that I am not unlike most residents in this regard, although there are probably many of us who hold the conceit that we are moved primarily by rational arguments. So I question, "What is the basis of this obviously irrational commitment?" Although it is difficult to make generalizations about individual motives, I think we can observe certain characteristics about the field as a whole that have made it attractive to those who have chosen it.

It appears to me that there are two fundamental underlying principles which have held me in the field and that, I suspect, have attracted other individuals to the field. First, in a world increasingly dominated by effective technologies, psychiatry is the last remaining, and probably the last possible, preserve of medical practice where the relationship between the physician and the patient is held to be the essential factor in healing. This is an old idea and lies at the heart of what it means to be a physician. This notion goes back to Aesculapius, and to the healing centers in Kos and Epidauros, when people 
would seek healing for a variety of ills from a therapeuti, through the classical god of healing who embodied himself in mortal physicians. Now, with the onslaught of scientific progress (the value of which we cannot deny), the interpersonal dimension of medical practice, and the efficacy of that dimension have all but dropped from view.

Psychotherapy is essentially a means of understanding and utilizing this relationship as a healing factor, regardless of the particular conceptual models used to describe it. If it is lost from psychiatric residencies, it will be lost to medicine as a whole. Certainly, I cannot imagine how professional identity can successfully encompass this value if it is explicitly devalued by the programs that help mold such identity.

This brings me to my second observation. It is fallacious to think of the field of psychiatry as an entity. It is, of course, helpful to do so at times. We organize ourselves and have conventions in order to promote mutual understanding and exchange of ideas, but, in fact, the field of psychiatry is composed of individuals. Psychiatry is an abstraction, just as being a psychiatrist is simply a role. But who fills these roles? If a pilot becomes a pilot because he likes to fly, then a psychiatrist becomes a psychiatrist because he is attracted to the psyche. What will happen if the psyche is driven out of psychiatry, or if psychotherapy training is driven out of psychiatric residency where professional identity is forged? The field would certainly change, and not just in terms of the kind of services it offers. More important, it will attract different kinds of people to fill its roles. Those individuals who have always been attracted to psychiatry precisely because it is the domain of medicine which most highly values, studies, and understands human relationships as they interact with illness and health, will go elsewhere.

We might think we are saving our necks, when actually we would be simply cutting our throats.

\section{THE FIRST STATEMENT FOR THE NEGATIVE BY DR. BLACK}

Twenty years ago this question would not have been asked. If a resident were so impertinent as to ask, he or she would have been met with an expression of incredulity. To believe otherwise would be heresy. That psychiatrists, first and foremost, were psychotherapists was taken as gospel.

This attitude toward psychotherapy has changed considerably over the past decade as questions of efficacy and cost have come to the foreground. The question has not gone away and is being asked more frequently. It is a rare psychiatrist who does not have an opinion about it. Like matters of faith and religion, there will be few converts; my aim, rather, is to stimulate the reader to give the matter thought and to look at it, momentarily, from another perspective.

Recommending that psychotherapy teaching be abolished in residency programs is not greeted with enthusiasm in many quarters. I suspect, also, that it 
will probably never fully come about. Ours is a pluralistic society. The mental health field will continue to respond to the needs and desires of the public, and psychotherapy appears to be both needed and desired. Practitioners will continue to be free to practice as they will, within the confines of accepted medical practice. I suspect that over time, however, my views will slowly be accepted, as the old guard fades away.

I shall not address the issue of psychotherapy's efficacy. I shall discuss the narrower issue - should psychotherapy be taught in residency programs? I say no. I will also address the underlying issue of how psychiatrists can best serve the community.

Manpower Shortage. Recent data from the Epidemiologic Catchment Area Study (ECA) documents what many have said for years: Many psychiatric patients go untreated, and many of the treated do not see psychiatrists (2). In addition, there are gross inequities in the distribution of care not only between the urban and rural setting, but also between state hospitals and academic centers $(3,4)$. It is clear that a large segment of the mentally ill are underserved, particularly the chronically ill, state hospital patients, the aged, children, and minorities.

That a general shortage of psychiatrists exists is well documented $(3,5,6)$. This has come about for many reasons including the decline in the number of American and foreign medical graduates entering psychiatry. For example, in 197011 percent of American medical school graduates entered psychiatry; today the figure is about 5 percent (3). It takes little imagination to see that current American psychiatric practice compounds this situation. Most American psychiatrists spend about 80 percent of their time as psychotherapists (3). Psychotherapy, even the innovative "brief therapies," is time consuming; this limits the number of patients a psychiatrist may treat. E. Fuller Torrey estimated that a practicing psychoanalyst may see as few as 80 patients in a lifetime (7).

In summary, there are great unmet needs in psychiatry that our current system is ineffectively dealing with, and this may be due, in part, to the practice of psychotherapy.

Role Diffusion. The function of today's psychiatrist overlaps greatly with other, non-M.D. mental health providers, such as social workers, psychologists, and nurses. All offer psychotherapy, and there are no data to suggest that one group provides better psychotherapy than another (8). Some practitioners have even gained legislative approval to diagnose and treat mental illnesses, as is the case with Ph.D. psychologists in Iowa, which further blurs the distinction.

Additionally, over the years psychiatrists have gradually assumed societal functions that have traditionally been assigned to social workers, the clergy, and educators. Examples include marriage counseling and family therapy.

Unbeknownst to most patients and legislators, however, psychiatrists have unique training and skills which set them apart from non-M.D. mental health providers. Traditionally, only physicians have been able to make complicated diagnoses, prescribe powerful drugs, and perform surgery (in our case, ECT). 
Psychotherapy is not something which sets M.D.s apart from others. Some even question whether it is a treatment at all, or merely an educational process not necessarily best suited to psychiatrists $(10)$.

In summary, this blurring of roles creates a situation wherein psychiatrists and psychiatric disorders are undervalued. Psychiatrists must redefine their scope and mission, and emphasize that which sets them apart from others-their medical background, hospital privileges, ability to diagnose, prescribe drugs, and perform ECT. Many of our best thinkers, including former APA President John Talbott, have made similar pleas (11).

Economics. The simple fact is that non-M.D. mental health professionals charge significantly less for psychotherapy than psychiatrists (12). In an era of shrinking funds, growing competition, and increasing consumer choice, it is not inconceivable that third party payors, including the government, will either lower the reimbursement offered psychiatrists for psychotherapy, or encourage a shift from psychiatrists to less costly practitioners including psychologists, social workers, and nurses. It is no wonder that in this climate the number of $\mathrm{Ph}$.D. psychologists is growing exponentially (12).

In summary, it makes sense to utilize psychiatrists for their unique skills and allow others to provide psychotherapy at lower cost. If psychiatrists do not take the lead in implementing this, I suspect it will be imposed on them.

Training of Residents. Psychotherapy, it is said, comes in over 250 varieties, from conventional types such as psychodynamic psychotherapy, to fringe therapies including arica, bioenergetics, and Z-therapy, though most have similar core features (13). There is little data to show that any of these has a particular advantage over another (14). This situation begs many questions: Which ones do we teach? Do we emphasize psychodynamics at the expense of behavior or group therapy? Do we emphasize any of these at the expense of learning diagnosis and somatic treatments? Do we aim for exposure, or do we aim for competence? These are important and difficult questions to answer.

Additionally, psychotherapy training is time consuming. A survey of the APA Burroughs-Wellcome fellows shows that we spend, on average, six to seven hours per week learning psychotherapy, excluding patient hours. This is an extraordinary investment in time for both resident and supervisor. One wonders if residents learning psychotherapy can stay abreast of current knowledge in psychiatry. At some point, there is a trade-off.

In summary, psychotherapy training is an inefficient use of a resident's time.

Conclusion. Needless to say, there are many arguments against training residents in psychotherapy including the four I have mentioned: 1) manpower; 2) role diffusion; 3) economics; and 4) residency training. Most of these condense into one concept; that is, we should be providing "the greatest good for the greatest number." Spending our time in psychotherapy does not allow this. I have several brief propositions: 
1. Psychiatrists must redefine their mission of treating the mentally ill, and not the "worried well";

2. Psychiatrists must reassert their leadership in a field increasingly devoid of leaders, and increasingly dominated by "co-equal team members." We are not equal! Psychiatrists have special training and skills that should be exploited for maximum patient benefit;

3. Psychiatrists must develop a referral pattern for psychotherapy, similar to the relationship between otolaryngologists and audiologists, or orthopedic surgeons and physical therapists;

4. Psychiatric residents should learn the fundamentals of psychotherapy, including theory, indications, and contraindications;

5. Just as there are pharmacology, forensic, and epidemiology fellowships available to residents, I suggest that there be psychotherapy fellowships available for those residents with a deep interest in this area, especially those who intend to pursue research.

\section{THE REBUTTAL FOR THE NEGATIVE BY DR. ASCHER}

There are many reasons that make our debate a pertinent and timely one. Dr. Black has discussed some that might compel us to eliminate psychotherapy from our training. I would like to amplify on one of them: the growing influence of neurobiology. There is a veritable explosion of knowledge concerning the biological basis of our thoughts, feelings, and behavior. Freud himself predicted this in his essay, “On Narcissism": "We must recollect that all our provisional ideas in psychology will presumably one day be based on an organic substructure" (15). Indeed, much of Freud's early efforts were attempts to understand the physical basis of mental illness, although from the late 1890 s on there is little or no mention of neurophysiology or neuroanatomy in any of his discussions. What structure remained took the form of entities such as id, ego, and superego. In computer language, Freud became almost entirely concerned with software elements, and disregarded the hardware. Apart from his and his successor's efforts, investigations of the hardware continued, forming the basis of what is now known as biological psychiatry. Armed with this rapidly growing technology, we are now better able to pursue the goal ultimately discarded by Freud.

Given the quickly emerging importance of brain biology, how can we best be prepared to deliver the type of care which is consistent with our training as physicians, while identifying us as unique contributors to the overall care of the mentally ill? The answer to this question is occurring as we speak. We will be learning more, not less, of brain biology and somatic interventions. There will be more, not fewer, psychotropic drugs available to us, and there will be more, not fewer, applications for the ones we now have. It follows that more, not less, time will have to be devoted to assimilating this growing data base and learning 
the fundamentals of somatic interventions. The biologic transformation of psychiatric training has already begun. Less time, and in some programs, no time, is being set aside for training in psychotherapy. We are in the midst of a change that will ultimately transform psychiatry into a biologically-based medical specialty.

In terms of training, it must now be determined which portions of psychodynamic theory are helpful and should be retained, and what must be added to qualify psychiatrists as experts in the delivery of mental health care that is biologically-based. First, what should remain of the former is the knowledge necessary to conduct a comprehensive interview allowing one to make a psychiatric diagnosis and, in so doing, be able to determine whether the illness is potentially responsive to a biologic intervention, a psychotherapeutic intervention, or both. Those falling into the first category would then be treated solely by a psychiatrist; those in the second by either a psychologist or social worker; and those in the third by a psychiatrist in true collaboration with a psychologist or social worker. Second, enough of psychodynamic training should remain that would sensitize the psychiatrist, or indeed any physician, to the nuances of human interaction that emerge when treating a physical illness.

Now what to add? We suggest that the essentials should include genetics and epidemiology of mental illness, diagnosis and classification, neurobiology, sociobiology, pharmacology, and somatic treatment. The list could go on, but what must be added to this new curriculum is the teaching of systems theory, which will help the resident not only to understand the patient as a biopsychosocial organism, but also to provide a practical context in the health care system in which he or she can operate cooperatively with other care givers. Finally, the time has come for us to intervene in a fashion which is consistent with our long years of training in the physical basis of illness.

\section{THE REBUTTAL FOR THE AFFIRMATIVE BY DR. MARKOWITZ}

My colleagues, Drs. Black and Ascher, have provided reasons why psychotherapy should not be taught to psychiatric residents. I admire their efforts, but find it hard to defend such a position. What should psychiatric residents be taught if not psychotherapy?

The goal of a resident's education should be the fullest understanding of the human mind, human behavior, and thought. To achieve this, one must learn neuroanatomy and the effects of drugs, transmitters, and hormones on the brain. But to gain the widest understanding of the mind, one must equally understand man's responses to stimuli, his modes of interaction with others, and his intrapsychic dynamics. To ignore behavioral, cognitive, strategic, psychodynamic, individual, family, and group psychotherapy would be to discard much of what we know of the mind, to severely narrow our outlook, and to eliminate much of the excitement and fascination of psychiatry. 
To learn theory is not enough; residents learn more by doing than by reading, and they must judge theory by their own experience. To learn psychotherapy, and perhaps especially psychodynamic psychotherapy, is no small task, and devoting much of residency to such work provides the beginnings of competence at best. Unless one learns psychotherapy during residency, the difficulty and expense may prevent it from being learned later. Furthermore, if not exposed to psychotherapy during their residency, few graduates would feel comfortable attempting to learn it later. While I think it is true, as Dr. Black has said, that there is a trade-off in learning different kinds of psychiatry, psychotherapy is among the most difficult and least changing areas of the field, and thus probably the one we should most focus on. Knowledge of medication, for instance, will inevitably change with time.

Why learn psychotherapy? First, it is a necessary part of the fullest understanding of the mind. This makes it not a redundant skill, but a fundamental one for the psychiatrist.

Second, psychotherapeutic skills, and especially psychodynamics, are essential for treating any patient. How can one understand the patient without an awareness of transference, countertransference, the doctor-patient relationship, and the patient's characterologic defenses? This is knowledge that not only psychiatric residents, but arguably all physicians, should have. Psychodynamic training is particularly critical as part of the resident's learning experience, and to his or her clinical introduction to the patient and to psychopathology; it continues to be crucial in any practice (16). Psychotherapy implies an awareness of the interaction with a patient, and the ability to manipulate that interaction. Thus, psychotherapy is a skill essential in dealing with patients. Since, regardless of psychiatric persuasion, seeing patients means doing psychotherapy, one might as well learn to do it well. Understanding the patient and communicating that understanding are key to the treatment of psychiatric patients, and only psychotherapy provides that key.

Although psychologists, social workers, and others practice psychotherapy, there are areas where they cannot compete. In these areas, which coincide with major foci of residency training, psychotherapy is particularly indispensible for the psychiatrist. For example, no other mental health worker can provide both psychotherapy and psychotropic medication. Psychiatrists are thus uniquely qualified to treat patients on medication with psychotherapy, over and above what Tom Gutheil has called the "pharmacotherapeutic alliance" (17). For consultation liaison, no other physician or mental health professional combines the knowledge of organic pathology, medication, and psychodynamic awareness as does the psychiatrist. Who else is as qualified to treat such patients with psychotherapy? Again, in the emergency room, only psychiatrists have the capability for making psychotherapeutic and pharmacologic interventions.

Dr. Black suggests that psychiatrists should evaluate and refer psychotherapy patients rather than treat them. Questions immediately arise, e.g., how can one evaluate for psychotherapy without some knowledge of the treatment? 
Again I would suggest that learning an abstract theory is insufficient-one needs to do it in order to understand it. There are patients for whom psychotherapies may be indicated or contraindicated. If they are indicated, which kind of treatment is most suitable? The wider the scope of one's training, the better one can evaluate and refer. Thus, even the diagnostic psychiatrist who does not practice psychotherapy should be trained in it. If there are really 250 kinds of psychotherapy, obviously not all can be taught, but a resident should have exposure to the major forms of treatment.

It has been shown that some forms of psychotherapy may be effective, and that it complements pharmacotherapy. It remains a significant part of our role definition. The only argument I can see for not teaching psychotherapy concerns residents' morale. Learning psychodynamic theory is a hard and humbling experience that leaves its pupils far less certain and secure in themselves and in their field than does psychopharmacology. Striking psychotherapy from the curriculum, while reducing the scope and complexity of psychiatry, may help preserve self-esteem. This may explain why psychiatric residents from certain programs report themselves so much happier in their residency experience than others.

Aside from this, I don't think Dr. Black's arguments are strong. Even if other mental health workers offer psychotherapy to patients at lower costs, residents need to keep psychotherapy in their curriculum, both for their own education and for those patients whom they are uniquely qualified to treat. The argument that psychotherapy is not the best use of psychiatrists is confounded by the recognition that psychotherapy is inherent in any encounter with a patient, and thus provides one of the best therapeutic tools we have.

This debate has served an educational purpose by forcing us to look carefully at what we generally take for granted in psychiatry. I find it appalling that the field has so changed that we can now question the value of psychotherapy to psychiatry. Has the time arrived when doctors no longer need to talk to patients? Surely not. Should advances in psychobiology lead us to ignore the long and carefully developed science of human behavior and interaction? If all the physical mechanisms of the brain were known, would that obviate an understanding of the mind or a knowledge of the person? Of course not. There is far more to our thoughts and emotions than the chemical and electrical processes behind them. Psychotherapy teaches us about ourselves and enables us to understand and help others in crucial, irreplaceable ways.

\section{CLOSING REMARKS BY DR. HAMBURG}

This debate is an ancient one, even older than psychiatry itself. At its heart lies the question of uncertainty with its attendant discomforts, which repeatedly evoke an attempt to expel change, doubt, and indeterminancy from scientific inquiry. The recurrent false hope is that what then remains proper to psychiatry, or to any science, will permit a new efficiency, a comforting order fulfilling 
our expectations for a modern medical specialty. From its diagnostic algorithms to its pharmacopeia, the purified field of psychiatry would consist only of measurable quantities. Banished outside its walls would be the energetic machine of self-inquiry, of chance-taking, in short, the whole interpersonal field which we call psychotherapy.

Of course, banishing psychotherapy from our profession may prove more difficult than expected. It is one thing to decide not to name the interpersonal, not to explore its meanings, not to become conversant with its disquieting ways, but it is quite another thing to exclude its power from our daily work. Simply ignoring transference and countertransference will not eliminate them from each encounter that we have with a patient.

There is a body of Western philosophical tradition, from Descartes to Popper, that has struggled to exclude uncertainty from scientific claims to knowledge. We might do well to remember that there is also a parallel history of return of the repressed. Recall, if you will, those restless atomic movements whose destinations we were never quite able to predict. Their uncertainty haunted physicists, forcing them to remark their double role as both observer and participant in the phenomena which they sought to comprehend. Can we really expect a different fate as we try to immobilize mental phenomena, weighing them on our assorted symptom scales? The excess, the supplement, that which always eludes measurement, inevitably returns to haunt us, laugh at us, and tantalize our fascination.

The struggle to exclude chance is not confined to removing psychotherapy from psychiatry; this debate has its echoes within the field of psychotherapy. While some seek more rigidly empirical definitions, a more formal reproducibility of interaction in a search for efficiency, others remain determined to keep the interpersonal field open to the indeterminant play of mutual inquiry. Dynamic psychotherapy remains distinguished by its explicit attention to the therapist's double movement in the therapeutic scene. We are at once observers and participants, looking within and toward the other. The therapist in his training has cultivated the capacity to tolerate being doubled in this way.

In this context, psychotherapy education cannot be seen simply as the acquisition of a therapeutic tool kit. In large measure it consists of nurturing mental capacities, including those of observing, self-inquiry, and suspending certainty. To teach therapy, besides the necessary didactic programs, it is necessary to focus on the articulation between self-knowledge and the experience of the other. This is the territory of psychotherapy.

Several experiences during my residency stand out as paradigms for the effective teaching of psychotherapy. I would like to describe three of them briefly.

For the past decade, Dr. Edward Messner has taught a first year seminar called "autognosis" (self-knowledge). During the first six months of that semin nar, residents review papers that deal with issues of transference. Each resident then prepares two seminar hours devoted to a personal experience that forged 
new knowledge of the self. The topics have always been diverse, with formats including music, dance, and photography, as well as the narrative. I remember the quiet atmosphere of these hours, permitting 12 of us to struggle with our feeling about patients and about ourselves. Besides the relevance of the material to our work, Dr. Messner's sustained capacity to create a safe place for open inquiry generated deeply personal presentations; it also became an enduring example of a therapeutic environment.

The T-group run by Dr. Irene Briggin has provided a second consistent focus for psychotherapy education. Besides offering a place to share the personal tribulations of our first year in psychiatry, Dr. Briggin's group was also a forum to discuss the experience of doing therapy. Without ever saying so, she proved that those distinct filaments of our attention, directed toward the patient at one moment and then inwards the next, were inextricably interwoven.

Individual supervision remains the heart of psychotherapy education. I want to describe one supervisory experience, with Dr. Ginger Chappell, because I believe it exemplifies a mode of teaching psychotherapy. At its best, supervision provides an envelope around therapy which permits it to grow in its own way, opening a possibility here or questioning a blind spot there, seldom controlling or intruding. For two years I noticed a sense of comfort about the patients I followed with Dr. Chappell, whatever the difficulties of their treatment. I did not hesitate to reveal my uncertainties about myself or my patients in her presence. Like Dr. Briggin in her leadership of the resident T-group, and Dr. Messner in his seminar, Dr. Chappell enacted the experience of the therapeutic space in the supervision, simultaneously permitting the inner worlds of the patient and the therapist to open.

In conclusion I would like to suggest that we dare to keep ourselves open to uncertainty, to keep taking chances in our profession. We must accept some inevitable consequences of our choice, whether they be existential, political or economic. I would also propose that we see psychotherapy education as the mutually validating, challenging, nurturing process that it ought to be, and that we restrain outselves from restricting its playfulness in a misguided search for comfortable, certain truth.

\section{REFERENCES}

1. Goodwin DW: Is psychodynamic theory of little relevance to modern psychiatric care? Los Angeles, CA, American Psychiatric Association Annual Meeting, May $5-11,1984$

2. Shapiro S, Skinner EA, Kessler LG, et al: Utilization of health and mental health services. Arch Gen Psychiatry 41:971-982, 1984

3. Talbott JA, Granet RB: Careers in psychiatry: options for the future. Compr Psychiatry 25:263-277, 1984

4. Eaton JS, Goldstein LS: Psychiatry in crisis. Am J Psychiatry 134:642-645, 1977

5. Knesper DJ: Documenting a shortage of psychiatrists: the repair shop model. Am J Psychiatry 137:1439-1442, 1980 
6. Lipzin B: The psychiatrist shortage. Arch Gen Psychiatry 36:1416-1419, 1979

7. Torrey EF: The Death of Psychiatry. Radnor, Chilton Books, 1974

8. Prioleau L, Murdock M, Brady N: An analysis of psychotherapy versus placebo studies. Behavioral and Brain Sciences 6:275-310, 1983

9. Winokur G: Gresham's law in psychiatric illness. J Clin Psychiatry 46:308, 1985

10. Karasu TB: Recent developments in individual psychotherapy. Hosp \& Comm Psychiatry 35:29-39, 1984

11. Psychiatrists must unite to survive, says Talbott. Psychiatric News 20:14-15, May 15, 1985

12. Wilkinson G: Psychotherapy in the marketplace. Psychol Med 14:23-26, 1984

13. Parloff MB: Psychotherapy research evidence and reimbursement decisions: Bambi meets Godzilla. Am J Psychiatry 139:7 18-727, 1982

14. Smith ML, Glass GV: Meta-analysis of psychotherapy outcome studies. Am J Psychol $32: 752-760,1977$

15. Freud S: On Narcissism. Standard Edition, 14:78, 1957

16. Michels R: The Place of Psychoanalysis in Psychiatric Residency Training, in The Role of Psychoanalysis in Psychiatric Education: Past, Present and Future. Edited by Pollock G, Thurnblad R, Weissman S. New York, International Universities Press (in press)

17. Gutheil T: The psychology of psychopharmacology. Bull Menninger Clinic 46:321330,1982 